\title{
Effects of Cigarettes Smoking on Pulmonary Function among University Students
}

\author{
Azian Hariri ${ }^{1, a}$ and Wan Mohd Mazdey Wan Mansor ${ }^{1}$ \\ ${ }^{1}$ Industrial and Indoor Environment Research Group (IIERG) \\ Centre for Energy and Industrial Environment Studies (CEIES), Faculty of Mechanical and Manufacturing Engineering, \\ Universiti Tun Hussein Onn Malaysia, 86400, Parit Raja, Batu Pahat, Johor, Malaysia
}

\begin{abstract}
Pulmonary function testing is a physiological test that measures how an individual inhales or exhales volumes of air as a function of time. Smoking is greatly associated with reduction of pulmonary function. This research is aimed to estimate the values of peak expiratory flow (PEF), forced expiratory volume in first second (FEV1), forced vital capacity (FVC) and ratio between FEV1/FVC among smoking and non-smoking students in Universiti Tun Hussein Onn Malaysia. Smoking is often related to obstructive disorder with low value of FVC, FEV1 and FEV1/FVC. These pulmonary functions were analyzed based on several variables such as; the number of cigarette smoked per day, duration of smoking, age, and body mass index (BMI) values. 70 healthy volunteers consist of smoking and non- smoking students was selected through several sessions. Students were interviewed to answer questionnaire on demographic, lifestyles and their smoking habit. The pulmonary function tests were conducted according to American Thoracic Society (ATS) standards. The results of the pulmonary functions were analyzed by using SPSS software to compare the pulmonary functions between the smoker and the non-smoker students. The results of the studies showed that the number of cigarettes smoked by respondent and the BMI values were the significant predictors of the decrease in FEV1/FVC values among university students
\end{abstract}

\section{Introduction}

The use of tobacco by adolescents remains a major public health concern worldwide. There are 1.2 billion smokers globally, of which more than $50 \%$ are young people. There are nearly 600 million tobacco users within the Southeast Asian countries, with the region contributing to about $50 \%$ of the global burden of tobacco users [1]. It is estimated that tobacco-related deaths will be the most important cause of deaths in developing countries by 2020 [2]. According to Global Adult Tobacco Survey 2011, 32.5\% of the respondents in Malaysia where tobacco smoker with the age between $15-24$ years [3].

It is estimated that tobacco related death will become 1 billion in the 21 st century compared to 100 million in the 20 th century. It is also estimated 1 person die every 6 seconds from a tobacco related diseases [4]. Cigarette smoking is the major cause of many chronic diseases, such as stroke, heart disease, chronic obstructive pulmonary disease (COPD), periodontal disease, peripheral vascular disease, pneumonia, lung and oral cancer [2], [5]. Lung is a directly affected organ by cigarette smoking. Various respiratory diseases including lung cancer, chronic obstructive pulmonary disease, interstitial lung diseases, bronchial asthma, are caused and worsen by cigarette smoking [6].

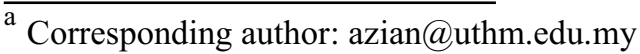

The degradation of lung function and the severity of respiratory disease can be identified by pulmonary function tests (PFTs) [7-9]. PFTs is a tools to measure the volumes of air during individual inhalation or exhalation process. The main parameters measured by PFT are the peak expiratory flow (PEF), forced expiratory volume in first second (FEV1), forced vital capacity (FVC) and ratio between FEV1/FVC.

Study conducted by Bano et. al in rural area of India concluded that smoker had 17.3 times more risk of having impaired pulmonary function as compared to non-smoker and obstructive pulmonary impairment was the commonest in smoker[10-11]. Study by Boskabady et. al in Iran also concluded smoking leads to increased respiratory symptom (cough, wheezing and tightness) and reduction of PFTs value [12]. Study done among Thailand youth between 15 to 18 years old lead to the conclusion of FVC value of nonsmoker were significantly greater than smoker. It is also highlighted that early effect of cigarette in youth can lead to problem with respiratory system [13].

There are limited study done to assess the pulmonary functions of young people especially that relate to young tobacco smoker mainly because the effects of smoking is believe to be significant for longer duration of tobacco smoking years, and may insignificant in young people with shorter duration of tobacco smoking years. However, in the last five decades, the anthropometric data of young adults 
have changed significantly owing to factors such as increasing body height, increasing body mass index, increasing air pollution level and decreased in physical activities [7]. Therefore, new pulmonary function data regarding young people, particularly young smokers and non-smokers are needed.

\section{Methodology}

\subsection{Questionnaire Interview}

The questionnaire interview questions were based on the following topics:

i. Demographic and health status (age, race, height, weight, previous pulmonary illness, asthma)

ii. Lifestyles (physical activities)

iii. Smoking habit (duration of smoking, the number of cigarette per day)

The questionnaire interviews were made to collect required variables that may correlate significantly with the pulmonary function results. It also conducted as screening tools to select healthy young university students that suitable to participate in this study. Students who exercised regularly/athletic or who had a history of or currently had obstructive or restrictive types of respiratory diseases and were taking treatment were excluded from this study. Student less than 19 years old or exceeding 29 years old or with excessive body mass index (BMI) was excluded. Only male students were asked to participate in this research to avoid inaccurate results due to limited sample of female student smokers. 70 students were divided into 2 main group of; smoker and non-smoker with the same sample size.

\subsection{Pulmonary Function Tests (PFTs)}

There are three distinct phases to the spirometry maneuver, as follows:
i. Maximal inspiration
ii. A "blast" of exhalation
iii. Continued complete exhalation to the end of test

The subject should inhale rapidly and completely from functional residual capacity, and the breathing tube should be inserted into the subject's mouth, making sure the lips are sealed around the mouthpiece and that the tongue does not occlude it. It is important that the preceding inspiration is fast and any pause at full inspiration be minimal (i.e., only for $1-2$ seconds). The test assumes a full inhalation before beginning the forced exhalation, and it is imperative that the subject takes a complete inhalation before beginning the maneuver [7]. Table 1 shows the pulmonary function parameters investigated in this study with definition. Each of these parameters was compared with the predicted value data from the spirometry software database (CareFusion Version 1.08) based on sex, age and height of the welders. The predicted value data were based on the healthy nonsmoking reference data taken during Pneumobile Project, Indonesia [14]. The results of pulmonary function were calculated in percentage predicted ( $\%$ predicted) as the following;

$$
\% \text { predicted }=\frac{\text { value recorded }}{\text { predicted value }} \times 100
$$

Table 1 The definitions of forced expiratory (FEV1), peak expiratory flow (PEF) and forced vital capacity (FVC) [7].

\begin{tabular}{|l|l|}
\hline Parameter & Definitions \\
\hline $\begin{array}{l}\text { Forced Vital Capacity } \\
\text { (FVC }\end{array}$ & $\begin{array}{l}\text { FVC is the total maximum } \\
\text { exhaled of individuals, which is } \\
\text { the ability maximum force } \\
\text { exhaled, expressed in litres / } \\
\text { sec. }\end{array}$ \\
\hline Forced Expiratory (FEV1) & $\begin{array}{l}\text { The volume delivered in the } \\
\text { first second of an FVC } \\
\text { manoeuvre } \\
\text { Peak Expiratory Flow } \\
\text { (PEF) }\end{array}$ \\
$\begin{array}{l}\text { The maximum expiratory flow } \\
\text { achieved from a maximum } \\
\text { forced expiration, starting } \\
\text { without hesitation from full } \\
\text { inspiration }\end{array}$ \\
\hline
\end{tabular}

Figure 1 shows the acceptability and repeatability criteria that need to be fulfilled for pulmonary function test. Flow should be measured from a series of at least three force expiratory curves that have an acceptable start of the test. The spirometer device needs to be calibrated daily with a 3$\mathrm{L}$ volume calibrator syringe (Kahntact 3L Volume Calibration Syringe Type 5570) for low, medium, and high flow for accurate results. 


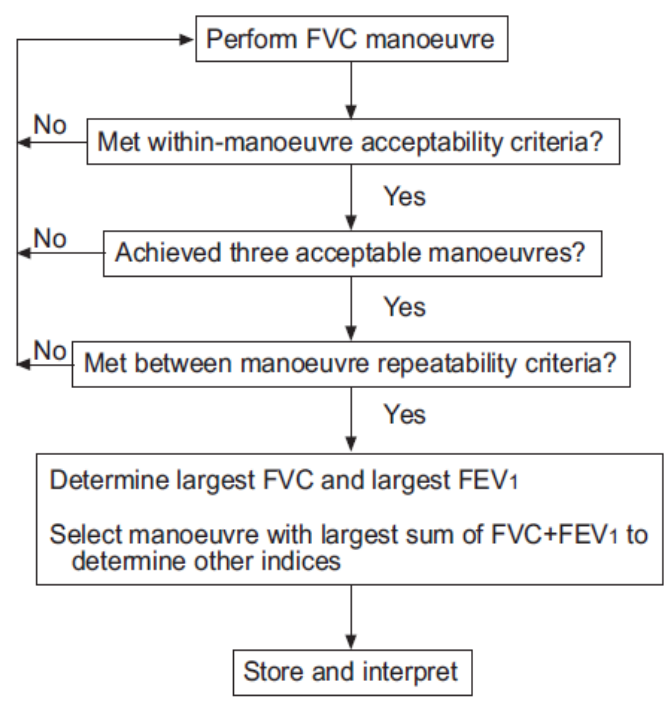

Figure 1 Acceptability and repeatability criteria for spirometric test [7]

\subsection{Statistical Analysis}

Statistical analysis was conducted to correlate and recognize the significant variables for the pulmonary functions. Statistical analysis was conducted by the SPSS software version 18 (SPSS Inc., Chicago). T-test analysis was used to compare mean pulmonary function parameters between smoker and non-smoker. Kendall's Tau-b correlation analysis was done to get association between smoking duration and smoking status (smoker or nonsmoker) with pulmonary function parameters. Further analysis using multiple regressions were conducted to confirm the predictors of the pulmonary functions. The level of significance is taken as $\mathrm{p}<0.005$.

\section{Results and Discussion}

The questionnaire is divided into four parts, A, B, C and D. Part $\mathrm{A}$ is a question about the demographics of the respondents, while part $\mathrm{B}$ is a question about their smoking activity information. In section $\mathrm{C}$ are questions about their health status information, and the next part $\mathrm{D}$ is about the status of their lifestyle information. A total of 70 respondents (35 smoker and 35 non-smoker) were taken into consideration in this study.

Data of the lung function tests (Mean + standard deviation (SD)) for 70 students are shown in Table 2. The mean age is 24.49 years for overall respondents with SD of 1.78 .

Table 2 The mean age of the respondents and the results of pulmonary function tests.

\begin{tabular}{|l|l|}
\hline Criteria & $\begin{array}{l}\text { N=70 } \\
\text { (Mean } \pm \text { SD) }\end{array}$ \\
\hline Age (Years) & $24.49 \pm 1.78$ \\
\hline FEV1 (\% predicted) & $81.23 \pm 8.56$ \\
\hline FVC (\% predicted) & $79.09 \pm 10.47$ \\
\hline PEF (\% predicted) & $79.83 \pm 9.01$ \\
\hline FEV1/FVC & $105.17 \pm 6.99$ \\
\hline
\end{tabular}

Table 3 shows the T-test analysis to compare the mean value of investigated pulmonary functions parameters of 35 smoking students and 35 non-smoking students. All investigated pulmonary functions parameters of FEV1, FVC, PEF and FEV1/FVC mean values were higher for the non-smoker students compare to the smoker students as expected. In addition, there is a significant correlation between FEV1 and FVC with smoking and non-smoking status among students as shown in Table 3. The finding on FVC value were on the same agreement with Tantisuwat et. al [13] and Nawafleh et.al [15].

Table 3 T-test results for different group

\begin{tabular}{|c|c|c|c|c|c|c|}
\hline Parameters & Group & $\mathbf{N}$ & Mean & SD & SE & Sig (2-tailed) \\
\hline FEV1 & $\begin{array}{l}\text { Smoker } \\
\text { Non-smoker }\end{array}$ & $\begin{array}{l}35 \\
35 \\
\end{array}$ & $\begin{array}{l}78.08 \\
84.37 \\
\end{array}$ & $\begin{array}{l}7.57 \\
8.43 \\
\end{array}$ & $\begin{array}{l}1.28 \\
1.43 \\
\end{array}$ & $.002 *$ \\
\hline $\mathrm{FVC}$ & $\begin{array}{l}\text { Smoker } \\
\text { Non-smoker }\end{array}$ & $\begin{array}{l}35 \\
35 \\
\end{array}$ & $\begin{array}{l}75.97 \\
82.20 \\
\end{array}$ & $\begin{array}{l}8.98 \\
11.03 \\
\end{array}$ & $\begin{array}{l}1.52 \\
1.86 \\
\end{array}$ & $.012 *$ \\
\hline PEF & $\begin{array}{l}\text { Smoker } \\
\text { Non-smoker }\end{array}$ & $\begin{array}{c}35 \\
35\end{array}$ & $\begin{array}{l}77.94 \\
81.71\end{array}$ & $\begin{array}{l}8.05 \\
9.63\end{array}$ & $\begin{array}{l}1.36 \\
1.63\end{array}$ & .080 \\
\hline FEV1/FVC & $\begin{array}{l}\text { Smoker } \\
\text { Non-smoker }\end{array}$ & $\begin{array}{c}35 \\
35 \\
\end{array}$ & $\begin{array}{l}104.4 \\
105.9 \\
\end{array}$ & $\begin{array}{l}6.53 \\
7.43 \\
\end{array}$ & $\begin{array}{l}1.10 \\
1.26 \\
\end{array}$ & .360 \\
\hline
\end{tabular}

$* \mathrm{p}<.005$ 
Table 4 shows Kendall's Tau-b correlation analysis to determine the correlation between lung function parameters with the number of cigarettes smoked per day, duration of smoking and BMI values. There was a significant correlation between FVC and the number of cigarettes smoked per day $(r=-.256$, two tailed $\mathrm{p}<.001)$. In addition, there is also a significant correlation between FEV1 with the number of cigarettes smoked per day $(r=$ -.288 , two tailed $\mathrm{p}<.001$ ).

There were also significant correlation between duration of smoking with FVC values $(\mathrm{r}=-.125$, two tailed $\mathrm{p}<.001)$ and FEV1 $(\mathrm{r}=-.151$, two tailed $\mathrm{p}<.001)$. A significant correlation was also found between the ratio of FEV1 /FVC with BMI values ( $\mathrm{r}=-.137$, two tailed $\mathrm{p}$ $<.001$ ). Results of the study showed a decrease in lung function of FVC and FEV1 values was correlated with the increased number of cigarettes smoked per day and duration of smoking among students while increase BMI values correlated with a decrease in FEV1 / FVC. These results clearly shows the obstructive lung symptoms were detected in smoker group of students which significantly correlates with the number of cigarettes smoked per day, duration of smoking and BMI values.

Table 4 The Kendall's tau-b correlation between lung functions parameters with the number of cigarettes smoked, duration of smoking and BMI.

\begin{tabular}{|l|c|c|c|c|}
\hline $\begin{array}{c}\text { Types of } \\
\text { questions }\end{array}$ & FVC & FEV1 & PEF & $\begin{array}{c}\text { FEV1/ } \\
\text { FVC }\end{array}$ \\
\hline $\begin{array}{l}\text { Number of } \\
\text { cigarettes } \\
\text { smoked } \\
\text { per day }\end{array}$ & $-.256^{* *}$ & $-.288^{* *}$ & .051 & .116 \\
\hline $\begin{array}{l}\text { Duration } \\
\text { of smoking }\end{array}$ & $-.125^{* *}$ & $-.151^{* *}$ & .072 & .058 \\
\hline $\begin{array}{l}\text { Body mass } \\
\text { index } \\
(B M I)\end{array}$ & .053 & .066 & .030 & $-.137^{* *}$ \\
\hline \begin{tabular}{l}
$* * p<.001$ \\
\hline
\end{tabular}
\end{tabular}

Table 5 shows the multiple regression analysis for the FEV1. The multiple regression analysis was performed to determine the significant predictor for the decrease in lung function. The multiple regression analysis showed that only the number of cigarettes smoked per day is the significant predictor for the decrease value in FEV1. Duration of smoking and BMI did not show a significant predictor for the decrease in FEV1.
Table 5 Analysis multiple regression for FEV1

\begin{tabular}{|l|l|l|l|}
\hline Types of questions & B & SE & $\beta$ \\
\hline Step 1 & \multicolumn{2}{|l|}{} \\
\hline Constant & 89.303 & 6.963 & \\
\hline $\begin{array}{l}\text { Number of } \\
\text { cigarettes smoked } \\
\text { per day }\end{array}$ & -.5 .401 & 1.743 & $-.644^{* *}$ \\
\hline Duration of smoking & 1.07 & .571 & .391 \\
\hline $\begin{array}{l}\text { Body mass index, } \\
\text { BMI }\end{array}$ & -.262 & .289 & .103 \\
\hline Step 2 & 83.090 & 1.296 & \\
\hline Constant & -5.352 & 1.74 & $-.638^{* *}$ \\
\hline $\begin{array}{l}\text { Number of } \\
\text { cigarettes smoked } \\
\text { per day }\end{array}$ & & \multicolumn{2}{|l|}{} \\
\hline Duration of smoking & 1.027 & .568 & .375 \\
\hline Step 3 & 83.593 & 1.287 & \\
\hline Constant & -2.713 & .963 & $-.323^{* *}$ \\
\hline $\begin{array}{l}\text { Number of } \\
\text { cigarettes smoked } \\
\text { per day }\end{array}$ & & \multicolumn{2}{|l}{} \\
\hline
\end{tabular}

Dependent variable: FEV1, $\quad * * \mathrm{p}<.001$

Table 6 shows results of the multiple regression analysis for the FVC. Results of the analysis showed only the number of cigarettes smoked per day is the significant predictor for the decrease values in FVC. Duration of smoking and BMI did not showed any significant predictor for the decrease in the FVC values.

Table 6 Analysis multiple regression for FVC.

\begin{tabular}{|l|l|l|l|}
\hline $\begin{array}{l}\text { Types of } \\
\text { questions }\end{array}$ & B & SE & $\beta$ \\
\hline Step 1 & \multicolumn{3}{|l|}{} \\
\hline Constant & 78.672 & 8.441 & \\
\hline $\begin{array}{l}\text { Number of } \\
\text { cigarettes smoked }\end{array}$ & -7.501 & 2.113 & $-.751^{* *}$ \\
\hline $\begin{array}{l}\text { Duration of } \\
\text { smoking }\end{array}$ & 1.685 & .692 & .503 \\
\hline $\begin{array}{l}\text { Body mass index, } \\
\text { BMI }\end{array}$ & .098 & .350 & .032 \\
\hline Step 2 & \multicolumn{3}{|l|}{} \\
\hline Constant & 80.996 & 1.562 & \\
\hline $\begin{array}{l}\text { Number of } \\
\text { cigarettes smoked } \\
\text { per day }\end{array}$ & -7.519 & 2.097 & $-.733^{* *}$ \\
\hline $\begin{array}{l}\text { Duration of } \\
\text { smoking }\end{array}$ & 1.701 & .685 & .508 \\
\hline Step 3 & 81.830 & 1.583 & \\
\hline Constant & -3.149 & 1.184 & $-.307^{* *}$ \\
\hline $\begin{array}{l}\text { Number of } \\
\text { cigarettes smoked } \\
\text { per day }\end{array}$ & \multicolumn{3}{|l}{} \\
\hline \multicolumn{2}{|l|}{ Dependent variable: FVC, $* *$ p $<.001$} & \\
\hline
\end{tabular}


Table 7 shows the results of multiple regressions analysis for the ratio of FEV1 / FVC. The multiple regression analysis showed that only BMI is a significant predictor for the decrease in the value of FEV1 / FVC. Duration of smoking and number of cigarettes smoked per day did not show any significant predictor for the decrease in the FEV1 / FVC values.

Table 7 Analysis multiple regression for FEV1/FVC.

\begin{tabular}{|c|c|c|c|}
\hline Types of questions & B & SE & $\beta$ \\
\hline \multicolumn{4}{|l|}{ Step 1} \\
\hline Constant & 116.734 & 6.013 & \\
\hline $\begin{array}{l}\text { Number of } \\
\text { cigarettes smoked } \\
\text { per day }\end{array}$ & .384 & 1.505 & .076 \\
\hline Duration of smoking & -.075 & .493 & .034 \\
\hline $\begin{array}{l}\text { Body mass index, } \\
\text { BMI }\end{array}$ & -.487 & .249 & $-.235^{* *}$ \\
\hline \multicolumn{4}{|l|}{ Step 2} \\
\hline Constant & 105.180 & 1.144 & \\
\hline $\begin{array}{l}\text { Number of } \\
\text { cigarettes smoked } \\
\text { per day }\end{array}$ & .476 & 1.536 & .069 \\
\hline Duration of smoking & -.155 & .501 & .069 \\
\hline \multicolumn{4}{|l|}{ Step 3} \\
\hline Constant & 105.104 & 1.11 & \\
\hline $\begin{array}{l}\text { Number of } \\
\text { cigarettes smoked } \\
\text { per day }\end{array}$ & .077 & .830 & .011 \\
\hline
\end{tabular}

Dependent variable: FEV1/FVC,$\quad * * \mathrm{p}<.001$

The significant relation between BMI and lung function parameters were also had been highlighted by Nawafleh et. al in study conducted in Jordan [15].

The results of pulmonary functions of investigated students cannot be compared directly with previous study from other researcher mainly due to the predicted set used were differs from one study to another. There were also difference existed in age and sex of the investigated subjects which had limit the comparison to be done between this study and previous study by other researcher

\section{Conclusion}

Investigation of pulmonary function among university students shows that the pulmonary function value of smokers was decreased compared to non-smokers. In addition, a significant correlation was found between the number of cigarettes smoked per day and duration of smoking with the decrease value of FVC and FEV1 of the smoking students. Besides that, the increase BMI values had shown a significant correlation with the decrease value of FEV1/FVC.

The results of the multiple regression analysis showed that the significant predictor of decrease in FEV1 and FVC values was the number of cigarettes smoked per day by respondent, while the decrease in value of FEV1/FVC was the influence of the BMI values.
In conclusion, smoking students had the lower pulmonary function values compared to non-smoking students.

\section{Acknowledgement}

This work was supported by the Fundamental Research Grant Scheme (FRGS) vote 1539 under the Malaysian Ministry of Higher Education (MOHE). The authors acknowledged Office for Research, Innovation, Commercialization and Consultancy Management (ORICC), Universiti Tun Hussein Onn Malaysia for the opportunities given. The authors gratefully acknowledged the technical support from Mr. Mohd Azizi bin Mohd Afandi during the operation of equipments used in this study.

\section{References}

1 N. Al-Sadat, a Y. Misau, Z. Zarihah, D. Maznah, and Tin Tin Su, Asia-Pacific journal of public health / Asia-Pacific Academic Consortium for Public Health, 22, p. 175S-180S, (2010).

2 R. A. Al-Naggar, S. A. R. Al-Dubai, T. Hamoud, R. Chen, and K. Al-Jashamy, Asian Pacific $J$ Cancer Prev, 12, pp. 619-624, (2011).

3 Malaysia Ministry of Health, Report of the Global Adult Tobacco Survey (GATS) Malaysia 2011, (2011).

4 Action on Smoking and Health, Tobacco Statistics and Facts, (2015).

5 D. B. Abrams, The 50th Anniversary SG Report, (2014).

6 Y. Ishii, Nihon Rinsho, pp. 416-420, (2013).

7 A. Bandyopadhyay, I. Bhattacharjee, R. Dalui, and S. Pal, Malaysian Journal of Medical Sciences, 20, pp. 17-25, (2013).

8 J. Macleod, R. Robertson, L. Copeland, J. Mckenzie, R. Elton, and P. Reid, British Journal of General Practice pp. 89-95, (2015).

9 A. Bandyopadhyay, Indian J Med Res, 134, pp. 653-657, (2011).

10 R. Bano, M. Am, K. Nb, N. Ahmad, and S. Nighute, World Health, 4, no. 1, (2009).

11 R. Bano, N. Ahmad, and A. M. Mahagaonkar, Walawalkar International Medical Journal, no 1, pp. 33-38, (2014).

12 M. H. Boskabady, M. Mahmoodinia, M. Boskabady, and G. R. Heydari, Revista Portuguesa de Pneumologia, 17, no. 5, pp. 199204, (2011).

13 A. Tantisuwat and P. Thaveeratitham, Journal of physical therapy science, 26, no. 2, pp. 167-70, (2014).

14 Ingelheim Boehringer, Pneumobile Project, Indonesia.,(1992).

15 H. A. Nawafleh and S. A.-S. A. Z. D. F. AlMaghaireh, Health Science Journal, vol. 6, no. 2, pp. 773-783, (2012). 